\title{
When people hear "doctor," most still picture a man
}

\author{
n Cite as: CMAJ 2019 March 11;191:E295-6. doi: 10.1503/cmaj.109-5723
}

Posted on cmajnews.com on Feb. 21, 2019.

$\mathrm{T}$ oday a physician is as likely to be female as male, yet most people still picture a doctor as a man. Only $5 \%$ of people presume a doctor will be female, according to a recent survey of 4000 Britons conducted by LinkedIn. Among people over age 55, that figure fell to just $2 \%$.

Receptionists, nursery teachers and nurses were the top three titles associated with women, with $63 \%$ of Brits presuming a nurse will be female. People were more likely to perceive traditional jobs as gendered and newer roles as more ambiguous. For example, $77 \%$ did not associate any gender with the title "search engine optimization specialist."
According to Dr. Natasha Larmie, a general practitioner in Hertfordshire, the results come as no surprise, even though nearly half of doctors in the United Kingdom are women. "I've often had people assume that I am a man when I go by my professional title."

It's a common bias, starting in childhood. One study found that seven of 10 primary school students in the UK identify surgeons as men and nurses as women. This may reflect who children see performing these roles. But gender biases tend to stick, even as the demographics of medicine change.

A Harvard study that found people were more likely to associate the name Jonathan with doctoring and Elizabeth with nursing also found that those biases didn't change after people were told the reverse was true. The stereotype acted as a "mental firewall" that prevented people from updating their perceptions as the facts changed.

Although patients often fare better when they receive care from women doctors, they tend to assume or prefer that doctors are men. One study asked people to choose between a male doctor, a female doctor, or whoever had the most experience, and more than $60 \%$ chose the male doctor. Just one in five preferred the most experienced doctor.

Even when women introduce themselves as doctors, they are often mistaken

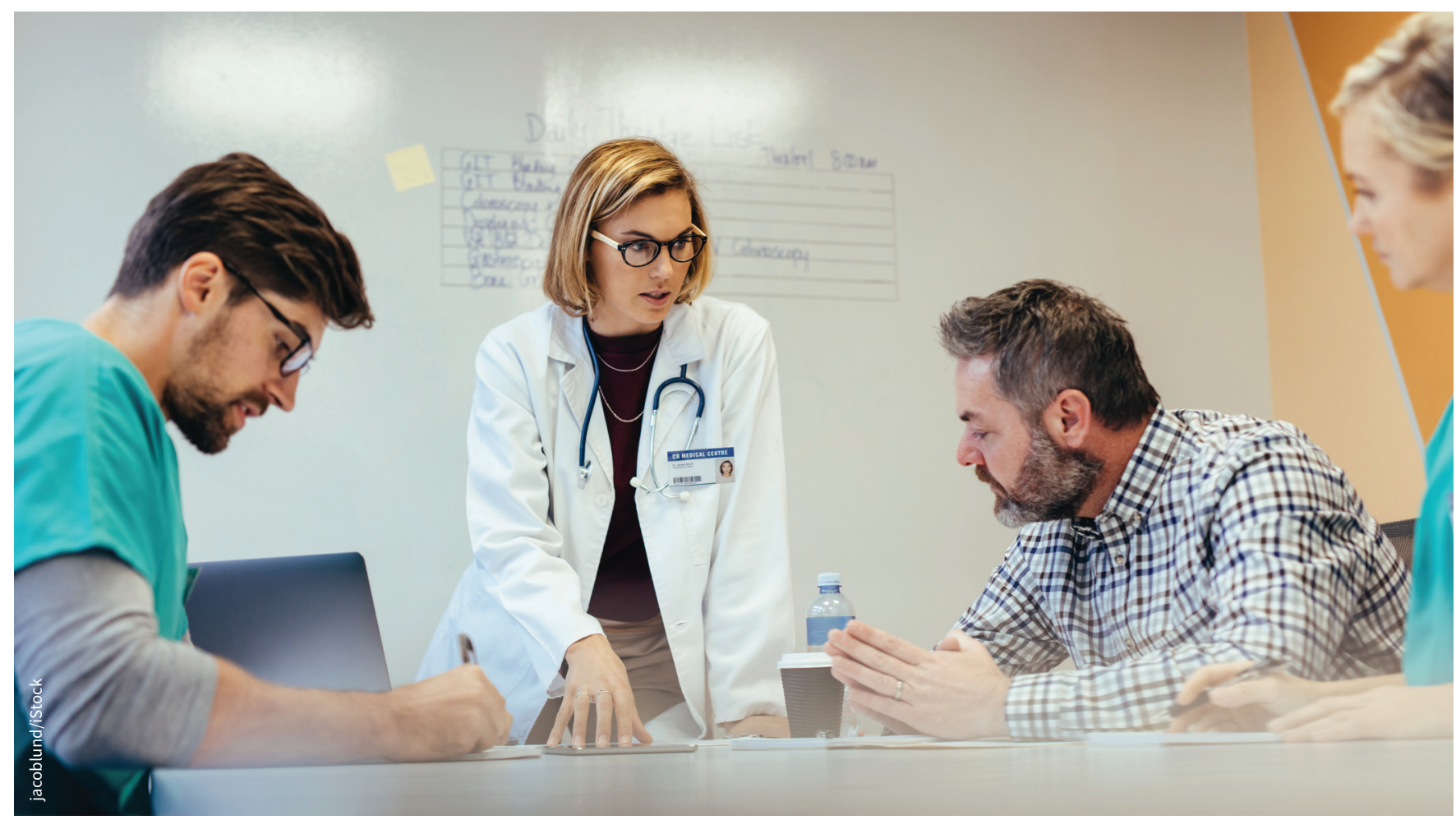

Gender bias remains rife in medicine despite growing numbers of women. 
for nurses or other staff, including by their colleagues. On a Reddit thread, some doctors described this happening several times a day. "It gets annoying, but you have to take it in stride or it will build resentment in you," one posted.

Dr. Julia Files studied the way doctors introduced their colleagues after noticing she was addressed informally when her male peers were not. She found that male physicians mostly introduced each other as "doctor," but used formal titles less than half the time when introducing female colleagues.

Women of color also report having to prove their medical credentials in situa- tions where white men do not. The case of a flight attendant refusing help from a black female physician during an inflight medical emergency triggered an outpouring of stories from women who were told to step aside because they weren't recognized as doctors. In some cases, they were at work and wearing a white coat.

Part of the problem may be a lack of women in leadership. In Canada, nearly $60 \%$ of students admitted to medical schools are female, and women make up $41 \%$ of all physicians. But they face an uphill battle to promotion. Women tend to receive lower-quality feedback that focuses on personality rather than skills.
Studies show wide gender disparities in academic rank, funding and publications.

Facing routine sexism from patients and colleagues, even when it doesn't rise to the level of harassment or assault, takes a toll. Female doctors are more likely to become burned out or depressed than their male peers or women in other fields. According to Dr. Saate Shakil and colleagues, "the impact of a cascade of small injustices that women physicians deal with every day undermines our daily work and collectively sends a demeaning message about our worth in the work place."

Lauren Vogel, CMAJ 